\title{
PPP Project Risk Assessment Evaluation Based on Cloud Model and D-S Theory
}

\author{
Li-Juan CHEN \\ Chongqing energy vocational college, chongqing, China \\ courageto2008@163.com \\ ${ }^{*}$ Corresponding author
}

\begin{abstract}
Keywords: PPP project, Cloud model, D-S theory, Risk assessment.
\end{abstract}
\begin{abstract}
In view of the fuzziness and randomness of risk factors of PPP project, a risk assessment method of PPP project based on cloud model and D-S theory is proposed. Firstly, it determines the reasonable PPP project risk evaluation index, and then uses the cloud model theory to divide the risk level of PPP project, then uses the D-S theory to determine the weight value of each risk evaluation index, finally establishes the comprehensive risk evaluation model of PPP project. Employing the "Chongqing HuanTou" PPP project with a number of districts and counties to conduct empirical tests. The results show that the cloud model and D-S theory can make the qualitative and quantitative evaluation of various risk factors inter-conversion and determine the weight of each risk index more accurately, which is scientific and reasonable. In addition, the cloud digital feature map can clearly and intuitively reflect the overall risk level of the project, which is of high reference value to the project decision-makers objectively evaluating the project risk.
\end{abstract}

\section{Introduction}

In the process of risk management of PPP project, the reasonable risk assessment is a prerequisite for making correct risk countermeasures. And the risk assessment method is divided into two categories: qualitative and quantitative (Degoff 2015). Each of which has its own advantages and disadvantages. The qualitative evaluation method requires the evaluator to relevant professional knowledge and engineering experience, and the quantitative evaluation method requires a large amount of reliable data. Therefore, scientific evaluation should combine qualitative and quantitative methods with complementary advantages and carry out more systematic analysis and evaluation.

In this paper, a cloud model is used to deal with the uncertainty problem, which indicates the principle of determining risk evaluation index and constructs the risk evaluation index system of PPP project. Firstly, there are twenty-three qualitative three-level risk assessment indicators by means of expert scoring, and then use the cloud forward generator to transform the qualitative evaluation set into quantitative data. By using the Dempster/Shafer theory(D-S), the numerical characteristics of the cloud model and the weight of the risk index are calculated by MATLAB software. Then, the comprehensive weight of each secondary risk assessment index is determined, and a comprehensive evaluation cloud map is drawn, the overall risk level of the project is determined according to the distribution of cloud map. By the actual case, it will improves the accuracy of evaluation results and the objectivity of evaluation results with the method of PPP project risk assessment based on cloud model and d-s theory.

\section{Index System of PPP Project Risk Evaluation}

Based on the analysis of the connotation and structure of risk management of PPP project, there are three levels evaluation index used to construct the risk evaluation index of PPP project (Tenah 2012). As shown in table 1 
Table 1 Risk evaluation index of PPP project

\begin{tabular}{|c|c|c|}
\hline One- level index & Second- level index & Third- level index \\
\hline \multirow{23}{*}{ The total risk $\mathrm{A}$} & \multirow[t]{3}{*}{ Political risk B1 } & The examination and approval delay \\
\hline & & Legal change $\mathrm{C} 12$ \\
\hline & & Government default $\mathrm{C} 13$ \\
\hline & \multirow{3}{*}{$\begin{array}{l}\text { Social environmental risk } \\
\text { B2 }\end{array}$} & macroeconomic change $\mathrm{C} 21$ \\
\hline & & Political opposition C22 \\
\hline & & War or riot $\mathrm{C} 23$ \\
\hline & \multirow[t]{3}{*}{ Financing risk B3 } & Financing structure unreasonable C31 \\
\hline & & Financing cost increased C32 \\
\hline & & Financing difficulties C33 \\
\hline & \multirow[t]{3}{*}{ Building risk B4 } & Design risk \\
\hline & & Construction risk $\mathrm{C} 42$ \\
\hline & & Completion risk $\mathrm{C} 43$ \\
\hline & \multirow{3}{*}{$\begin{array}{l}\text { Natural environmental } \\
\text { riskB5 }\end{array}$} & Bad weather C51. \\
\hline & & Unfavorable geological conditions C52. \\
\hline & & Natural force majeure C53 \\
\hline & \multirow[t]{3}{*}{ Operational risk B6 } & Operating cost overrun C61 \\
\hline & & Low operating efficiency C62 \\
\hline & & The operation service quality is not good C63 \\
\hline & \multirow[t]{5}{*}{ Earnings risk B7 } & Income is insufficient C71 \\
\hline & & Material fee increases C72 \\
\hline & & Tax change $\mathrm{C} 73$ \\
\hline & & Market demand changes C74 \\
\hline & & Market uniqueness C75 \\
\hline
\end{tabular}

\section{The Definition of Cloud Model}

The cloud model is a transformation model between the qualitative concept and the quantitative value( Chan A 2014). which fully considering the fuzziness and the randomness of the concept of language problems. In addition, the quantitative data distribution law and scope of the concept can be obtained based on the analysis of the qualitative information. At the same time, the quantitative value can be effectively converted into the easy-to-understand language value, which provides a new way for the qualitative and quantitative evaluation of PPP projects.

Let $X$ be a set, that is, $X=\{X\}$, which is called the theory of domain. In the domain $X$, for any element $X$ of fuzzy set $A$, there is $A$ random number that tends to be stable. $\mu \tilde{A}(x)$ is called the membership of $X$ to $A$. If the domain is composed of simple and ordered elements, then the set $X$ is the basic variable. At this time, the distribution of membership degree on $\mathrm{X}$ is called the subordinate cloud; If there are not simple and orderly elements, it can also mapping to another a simple orderly universe ' $\mathrm{X}$ by the law $\mathrm{f}$, then $\mathrm{X}$ 'has only one $\mathrm{X}$ ' corresponds to it, namely $\mathrm{X}$ ' variables, on the basis of in the same way, the distribution of membership on $\mathrm{X}$ 'is called a subordinate cloud $(\mathrm{Xu} Y$ 2015).

The cloud model has three numerical characteristics: Expected value, Entropy and Hyper Entropy. Ex representation of the expectation of cloud droplets within the scope of domain distribution is the main basis for qualitative judgment. Ex representation of the expectation of cloud droplets within the scope of domain distribution, which is the main basis for qualitative judgment. Entropy represents qualitative measurement, the flatter of the cloud model, the more macroscopic and uncertain the measurement concept is. The entropy is determined by the randomness and fuzziness of the concept. The Hyper entropy refers to the uncertainty of entropy, namely the entropy of entropy, which reflects the cohesiveness measurement of the value of each value subordinate to the evaluation language, namely the dispersion degree of cloud droplets. The greater the value of the Hyper entropy, the greater the dispersion degree of the cloud, the less stable the evaluation measurement tendency is, , the trend line is wider in the cloud picture. In the same way, the entropy size is determined by the randomness of the entropy concept and the degree of fuzziness. The three digital features of the cloud model are shown in figure 1, where $E x=0.5, E n=0.10, \mathrm{He}=0.005$, and $\mathrm{n}=5000$. 


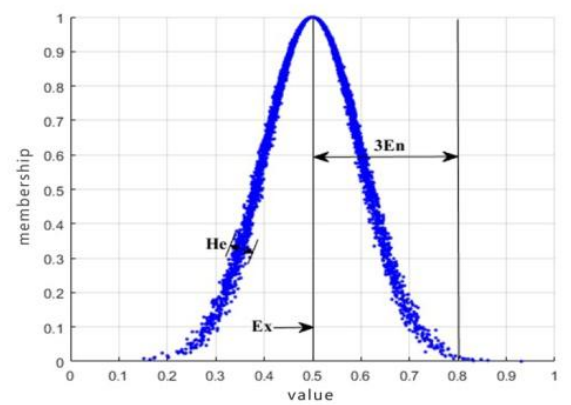

Fig. 1 Cloud model digital feature cloud map

\section{One-dimensional Cloud Generator}

Cloud generator is a kind of hardware implementation method of cloud generation algorithm, with positive and backward points. Through the forward (reverse) cloud generator, the mutual transformation between qualitative and quantitative concepts can be achieved, and its principle is shown in figure 2.

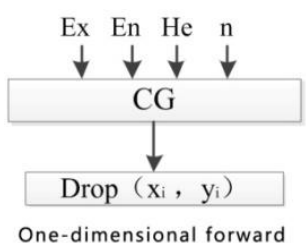

One-dimensional forward

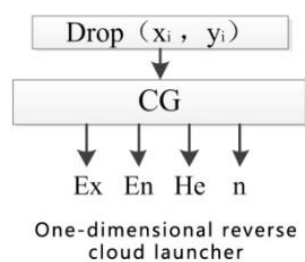

cloud launcher
climensional revers

Fig.2 principle of one-dimensional cloud generator.

\section{Risk Assessment Level under Cloud Model}

This paper divides the risk of PPP project into five grades. $\mathrm{Gi}=\{\mathrm{g} 1, \mathrm{~g} 2 \ldots \mathrm{G} 5\}=\{(\mathrm{I})$ low risk, low risk (II), medium risk (III), higher risk (IV), high risk (V)\}, and take the corresponding expected value, Exi $(\mathrm{I}=1,2 \ldots 5)$ 0,0.25, 0.50, 0.75, 1.00, the entropy value is $\mathrm{En}=0.045$, and the Hyper entropy $=0.005$, and the get the rating set of risk assessment (Laurini 2013). Which will be showed as follow:

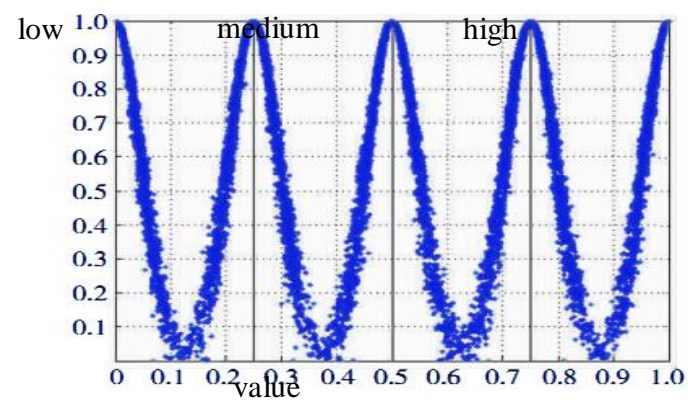

Fig. 3 Evaluation set in the cloud model

\section{Determination of Weight Coefficient Based on D-S Theory}

\section{The Overview Theory of the D-S}

The D-S is a kind of reasoning method to deal with the fuzzy information ability. The recognition framework of the evidence theory is a complete set consisting of all possible and incompatible basic propositions (assumptions), only one of them is true.

The basic probability distribution function, propositional trust function and propositional likelihood function are respectively defined as $\mathrm{M}$, Bel and PI. If there is $\mathrm{A} \subseteq \Omega$, then

$$
\begin{aligned}
& M(\Phi)=0 ; \sum M(A)=1 \\
& \operatorname{Bel}(A)=\sum_{B \leq A} M(B) ; P I(A)=1-\operatorname{Bel}(-A)
\end{aligned}
$$


And $M(A), \operatorname{Bel}(A), \operatorname{PI}(A)$ is called the basic trusted number, the propositional trust function domain and the propositional likelihood function domain. $M(A)$ represents the degree of $\mathrm{A}$, which indicates the total trust of $\mathrm{A}, \operatorname{Bel}(A)$ represents the degree of true trust of $\mathrm{A}$, and $\operatorname{PI}(A)$ is the measure of the degree of ambiguity that A is likely to be established.

\section{The Synthesis Rules}

Synthesis rules is one of the core content of D - S evidence theory, M1 and M2 are the same recognition evidence framework on $2^{\Omega}$, the orthogonal and $\mathrm{M}=\mathrm{M} 1+\mathrm{M} 2$,

$M(\Phi)=0, A=\Phi$

$M(A)=c^{-1}, \sum_{A \cap A A_{2}=A} M_{1}\left(A_{1}\right) M_{2}\left(A_{2}\right), A \neq \Phi \quad c=1-\sum_{A_{1} \cap A_{2}=\Phi} M_{1}\left(A_{1}\right) M_{2}\left(A_{2}\right)=\sum_{A_{1} \cap A_{2} \neq \Phi} M_{1}\left(A_{1}\right) M_{2}\left(A_{2}\right)$

Similarly, if there are the same identification framework of the evidence such as M1, M2,...Mn and so on ,and there will $\mathrm{M}=\mathrm{M} 1+\mathrm{M} 2+\ldots+\mathrm{Mn}$ (Targowsk 2015).

\section{The Weight Coefficient}

This research adopts the d-s theory to determine the weight coefficient, which can greatly reduce the inaccuracy of the fusion data caused by the obvious conflict between the data.

\section{Comprehensive Risk Assessment Model of PPP Project}

After each data sample point is identified by experts, the qualitative evaluation will be changed into quantitative data through positive cloud generator, according to $x_{i}$ to calculate the sample mean, first order sample absolute center distance and the sample variance, and the sample mean is: $\bar{X}=\frac{1}{n} \sum_{i=1}^{n} x_{i},(4)$ Absolute center distance of first order sample: $\frac{1}{n} \sum_{i=1}^{n}\left|x_{i}-\bar{X}\right|$ (5), Sample variance: $S^{2}=\frac{1}{n-1} \sum_{i=1}^{n}(x i-\bar{X})^{2}(6)$

According to the results of the formula(4),(5),(6) the numerical characteristics has been: $E_{x}=\bar{X}(7), E_{n}=\sqrt{\frac{1}{2 \pi}} \frac{1}{n} \sum_{i=1}^{n}\left|x_{i}-\bar{X}\right|,(8) H_{e}=\sqrt{\frac{1}{20}\left|S^{2}-E_{n}^{2}\right|}$, (9)

Then, according to the fusion algorithm in the cloud model, the evaluation cloud of each single factor is integrated, and the comprehensive cloud digital features of the PPP project risk evaluation are obtained. $E_{x}=\frac{\sum_{i=1}^{n} \lambda_{i} E_{x}}{\sum_{i=1}^{n} \lambda_{i}}, E_{n}=\frac{\sum_{i=1}^{n} \lambda_{i}{ }^{2} E_{m i}}{\sum_{i=1}^{n} \lambda_{i}{ }^{2}}, H_{e}=\frac{\sum_{i=1}^{n} \lambda_{i}{ }^{2} H_{i}}{\sum_{i=1}^{n} \lambda_{i}{ }^{2}}(10)$

\section{The Case Analysis}

Recently, in Chongqing, as the development of the municipal infrastructure construction and the reform of the ecological and environmental protection investment and financing system, in order to reduce the pressure of government investment, promote the environmental pollution to a third party, to realize the goal of universal coverage area county town sewage treatment infrastructure, the "Chongqing HuanTou" has made several contracts with most of the towns on the sewage treatment plan. The total investment reached 6.1 billion.

\section{Comprehensive Evaluation of PPP Project Risk}

This research has discussed the risk degree of the project by the cloud model and d-s theory . Firstly, there have third-level index evaluation of the system (table 2) gave by eight experts from different companies in the industry. And then used the cloud generator complete positive transformation between qualitative and quantitative, have to place corresponding quantitative data. Furthermore, the results were brought into equation (4) (9) to obtain the comprehensive cloud numerical characteristics of each secondary index (table 3).Again by professionals and a comprehensive evaluation to the secondary indexes, namely each secondary index influence on overall risk was given, as shown in table 4. 
Table 2 Qualitative assessment of risk level by experts

\begin{tabular}{|c|c|c|c|c|c|c|c|c|}
\hline index & Expert 1 & Expert 2 & Expert 3 & Expert 4 & Expert 5 & Expert 6 & Expert 7 & Expert 8 \\
\hline $\mathrm{C}_{11}$ & I & II & I & III & IV & II & II & II \\
\hline $\mathrm{C}_{12}$ & II & $\mathrm{I}$ & II & $\mathrm{I}$ & $\mathrm{I}$ & II & $\mathrm{I}$ & $\mathrm{I}$ \\
\hline $\mathrm{C}_{13}$ & III & $\mathrm{V}$ & $\mathrm{V}$ & III & II & $\mathrm{I}$ & $\mathrm{I}$ & II \\
\hline $\mathrm{C}_{21}$ & III & III & III & $\mathrm{I}$ & II & $\mathrm{I}$ & III & II \\
\hline $\mathrm{C}_{22}$ & II & $\mathrm{I}$ & II & II & II & II & II & II \\
\hline $\mathrm{C}_{23}$ & I & I & I & I & II & I & II & II \\
\hline $\mathrm{C}_{31}$ & III & $\mathrm{V}$ & IV & IV & $\mathrm{I}$ & IV & III & III \\
\hline $\mathrm{C}_{32}$ & $\mathrm{~V}$ & $\mathrm{~V}$ & $\mathrm{~V}$ & $\mathrm{~V}$ & IV & III & III & IV \\
\hline $\mathrm{C}_{33}$ & $\mathrm{~V}$ & III & III & II & $\mathrm{V}$ & II & III & $\mathrm{V}$ \\
\hline $\mathrm{C}_{41}$ & II & $\mathrm{I}$ & $\mathrm{I}$ & II & III & II & II & II \\
\hline $\mathrm{C}_{42}$ & II & $\mathrm{I}$ & II & III & $\mathrm{I}$ & III & III & $\mathrm{I}$ \\
\hline $\mathrm{C}_{43}$ & II & II & $\mathrm{I}$ & II & II & II & III & II \\
\hline $\mathrm{C}_{51}$ & II & $\mathrm{I}$ & II & III & $\mathrm{I}$ & $\mathrm{I}$ & II & II \\
\hline $\mathrm{C}_{52}$ & III & $\mathrm{V}$ & III & III & II & II & II & I \\
\hline $\mathrm{C}_{53}$ & II & $\mathrm{I}$ & II & $\mathrm{I}$ & $\mathrm{I}$ & III & II & II \\
\hline $\mathrm{C}_{61}$ & $\mathrm{~V}$ & II & III & III & III & IV & III & III \\
\hline $\mathrm{C}_{62}$ & III & $\mathrm{V}$ & II & IV & IV & II & II & $\mathrm{I}$ \\
\hline $\mathrm{C}_{63}$ & III & II & III & II & $\mathrm{V}$ & III & III & III \\
\hline $\mathrm{C}_{71}$ & IV & $\mathrm{V}$ & III & II & I & III & II & II \\
\hline $\mathrm{C}_{72}$ & III & II & IV & II & IV & III & IV & $\mathrm{I}$ \\
\hline $\mathrm{C}_{73}$ & II & III & III & I & II & II & II & III \\
\hline $\mathrm{C}_{74}$ & $\mathrm{I}$ & II & $\mathrm{I}$ & II & II & III & III & II \\
\hline $\mathrm{C}_{75}$ & I & II & IV & II & IV & II & III & $\mathrm{I}$ \\
\hline
\end{tabular}

Table 3 Qualitative transformation and corresponding cloud digital characteristics

\begin{tabular}{|c|c|c|c|c|c|c|c|c|c|}
\hline index & Expert1 & Expert2 & Expert3 & Expert4 & Expert5 & Expert6 & Expert7 & Expert8 & $\begin{array}{c}\text { Cloud } \\
\text { characteristics }\end{array}$ \\
\hline $\mathrm{C}_{11}$ & 0.00 & 0.25 & 0.00 & 0.50 & 1.00 & 0.25 & 0.25 & 0.25 & $\mathrm{E}_{\mathrm{x} 1}=0.4025$ \\
\hline $\mathrm{C}_{12}$ & 0.25 & 0.00 & 0.25 & 0.00 & 0.00 & 0.25 & 0.00 & 0.00 & $\mathrm{E}_{\mathrm{n} 1}=0.0276$ \\
\hline $\mathrm{C}_{13}$ & 0.50 & 0.75 & 0.75 & 0.50 & 0.25 & 0.00 & 0.00 & 0.25 & $\mathrm{H}_{\mathrm{e} 1}=0.0084$ \\
\hline $\mathrm{C}_{21}$ & 0.50 & 0.50 & 0.50 & 0.00 & 0.25 & 0.00 & 0.50 & 0.25 & $\mathrm{E}_{\mathrm{x} 2}=0.3124$ \\
\hline $\mathrm{C}_{22}$ & 0.25 & 0.00 & 0.25 & 0.25 & 0.25 & 0.25 & 0.25 & 0.25 & $\mathrm{E}_{\mathrm{n} 2}=0.0341$ \\
\hline $\mathrm{C}_{23}$ & 0.00 & 0.00 & 0.00 & 0.00 & 0.25 & 0.00 & 0.25 & 0.25 & $\mathrm{H}_{\mathrm{e} 2}=0.0086$ \\
\hline $\mathrm{C}_{31}$ & 0.50 & 0.75 & 1.00 & 0.00 & 0.00 & 1.00 & 0.50 & 0.50 & $\mathrm{E}_{\mathrm{x} 3}=0.5001$ \\
\hline $\mathrm{C}_{32}$ & 0.75 & 0.75 & 0.75 & 1.00 & 1.00 & 0.50 & 0.50 & 1.00 & $\mathrm{E}_{\mathrm{n} 3}=0.0295$ \\
\hline $\mathrm{C}_{33}$ & 0.75 & 0.50 & 0.50 & 0.75 & 0.75 & 0.25 & 0.50 & 0.75 & $\mathrm{H}_{\mathrm{e} 3}=0.0131$ \\
\hline $\mathrm{C}_{41}$ & 0.25 & 0.00 & 0.00 & 0.25 & 0.50 & 0.25 & 0.25 & 0.25 & $\mathrm{E}_{\mathrm{x} 4}=0.3617$ \\
\hline $\mathrm{C}_{42}$ & 0.25 & 0.00 & 0.25 & 0.25 & 0.00 & 0.50 & 0.50 & 0.00 & $\mathrm{E}_{\mathrm{n} 4}=0.0319$ \\
\hline $\mathrm{C}_{43}$ & 0.25 & 0.25 & 0.00 & 0.50 & 0.25 & 0.25 & 0.50 & 0.25 & $\mathrm{H}_{\mathrm{e} 4}=0.0046$ \\
\hline $\mathrm{C}_{51}$ & 0.25 & 0.00 & 0.25 & 0.25 & 0.00 & 0.00 & 0.25 & 0.25 & $\mathrm{E}_{\mathrm{x} 5}=0.3408$ \\
\hline $\mathrm{C}_{52}$ & 0.50 & 0.75 & 0.05 & 0.50 & 0.25 & 0.25 & 0.25 & 0.00 & $\mathrm{E}_{\mathrm{n} 5}=0.0301$ \\
\hline $\mathrm{C}_{53}$ & 0.25 & 0.00 & 0.25 & 0.00 & 0.00 & 0.50 & 0.25 & 0.25 & $\mathrm{H}_{\mathrm{e} 5}=0.0043$ \\
\hline $\mathrm{C}_{61}$ & 0.75 & 0.25 & 0.50 & 0.50 & 0.50 & 1.00 & 0.50 & 0.50 & $\mathrm{E}_{\mathrm{x} 6}=0.4167$ \\
\hline $\mathrm{C}_{62}$ & 0.50 & 0.75 & 0.25 & 1.00 & 1.00 & 0.25 & 0.25 & 0.00 & $\mathrm{E}_{\mathrm{n} 6}=0.0246$ \\
\hline $\mathrm{C}_{63}$ & 0.50 & 0.25 & 0.50 & 0.25 & 0.75 & 0.50 & 0.50 & 0.50 & $\mathrm{H}_{\mathrm{e} 6}=0.0109$ \\
\hline $\mathrm{C}_{71}$ & 1.00 & 0.75 & 0.50 & 0.25 & 0.00 & 0.50 & 0.25 & 0.25 & \multirow{2}{*}{$\mathrm{E}_{\mathrm{x} 7}=0.4571$} \\
\hline $\mathrm{C}_{72}$ & 0.50 & 0.25 & 1.00 & 0.25 & 1.00 & 0.50 & 1.00 & 0.00 & $\mathrm{E}_{\mathrm{n} 7}=0.0204$ \\
\hline $\mathrm{C}_{73}$ & 0.25 & 0.50 & 0.50 & 0.00 & 0.25 & 0.25 & 0.25 & 0.50 & $\mathrm{H}_{\mathrm{e} 7}=0.0120$ \\
\hline $\mathrm{C}_{74}$ & 0.00 & 0.25 & 0.00 & 0.25 & 0.25 & 0.50 & 0.50 & 0.25 & \\
\hline $\mathrm{C}_{75}$ & 1.00 & 0.25 & 1.00 & 0.25 & 1.00 & 0.25 & 0.50 & 0.00 & \\
\hline
\end{tabular}


Table 4 The weight coefficient of second-level index and the integrated weight after fusion

\begin{tabular}{|c|c|c|c|c|c|c|c|c|c|}
\hline \multirow{2}{*}{ index } & \multicolumn{8}{|c|}{ Weight coefficient } & \multirow{2}{*}{$\begin{array}{l}\text { The comprehensive } \\
\text { weights }\end{array}$} \\
\hline & Expert1 & Expert2 & Expert3 & Expert4 & Expert5 & Expert6 & Expert7 & Expert8 & \\
\hline $\mathrm{B}_{1}$ & 0.15 & 0.25 & 0.15 & 0.10 & 0.20 & 0.10 & 0.20 & 0.10 & 0.1571 \\
\hline $\mathrm{B}_{2}$ & 0.30 & 0.10 & 0.10 & 0.20 & 0.20 & 0.20 & 0.15 & 0.25 & 0.1885 \\
\hline $\mathrm{B}_{3}$ & 0.45 & 0.50 & 0.15 & 0.40 & 0.35 & 0.15 & 0.45 & 0.40 & 0.9236 \\
\hline$\overline{B_{4}}$ & 0.25 & 0.45 & 0.25 & 0.25 & 0.10 & 0.25 & 0.25 & 0.30 & 0.2953 \\
\hline $\mathrm{B}_{5}$ & 0.20 & 0.20 & 0.35 & 0.15 & 0.20 & 0.30 & 0.35 & 0.20 & 0.2513 \\
\hline $\mathrm{B}_{6}$ & 0.15 & 0.30 & 0.30 & 0.10 & 0.20 & 0.10 & 0.35 & 0.25 & 0.2199 \\
\hline $\mathrm{B}_{7}$ & 0.10 & 0.35 & 0.35 & 0.25 & 0.15 & 0.25 & 0.15 & 0.25 & 0.2325 \\
\hline
\end{tabular}

The results are: $\mathrm{Ex}=0.4065, \mathrm{En}=0.0286, \mathrm{He}=0.0098$, and the overall risk level cloud of the PPP project is obtained, as shown in fig.4.

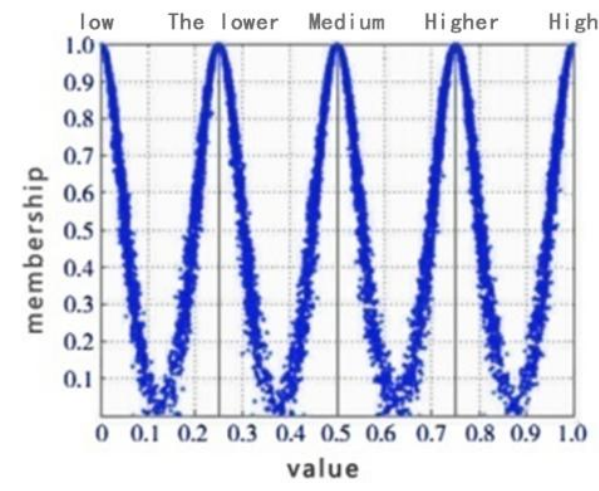

Fig. 4 Risk assessment cloud

As can be seen from figure 4 , the concentration of cloud droplets is between 0.350 and 0.475 , and the density distribution is around 0.43 .

The overall risk level of the PPP project is "medium" according to the evaluation set defined in the previous article, indicating that the overall risk level of the project is moderate

\section{Conclusion}

The results show that the evaluation model of PPP project based on cloud model and d-s theory is feasible, and the accuracy of evaluation result is improved compared with the common evaluation model.

\section{References}

[1] Targowsk, A. S. \& Rienzo, T. F, Managing Through systems Architecture: The Systems Logic Integration Approach. Information Systems Management, (2015) Vol. 3, No. 3, Pages 56-59.

[2] Laurini, R. \& Thompson, D. Fundamentals of Spatial Information Systems, London: Academic Press (2013).

[3] Tenah, K. Design-build approach: an overview, Cost Engineering, (2012), 31-37.

[4] Degoff, R. A, Construction Management, NewYork: wiley(2015).

Duncan, W. R, A Guide to the Project Management: Body of Knowledge, USA: Project Management Institue(2014).

[5] Chan A, Yeung J, Yu C, et al. Empirical Study of Risk Assessment and Allocation of Public-Private Partnership Projects in China[J]. Journal of Management in Engineering, 2016, 27(3).:136-148.

[6] Xu Y, Yeung J F Y, Chan A P C, et al. Developing a risk assessment model for PPP projects in China - A fuzzy synthetic evaluation approach[J].Automation in Construction, 2014, 19(7)::929-943. 